\title{
Development of an Open Rotor Cycle Model in NPSS Using a Multi-Design Point Approach
}

Eric S. Hendricks

Glenn Research Center, Cleveland, Ohio 


\section{NASA STI Program . . . in Profile}

Since its founding, NASA has been dedicated to the advancement of aeronautics and space science. The NASA Scientific and Technical Information (STI) program plays a key part in helping NASA maintain this important role.

The NASA STI Program operates under the auspices of the Agency Chief Information Officer. It collects, organizes, provides for archiving, and disseminates NASA's STI. The NASA STI program provides access to the NASA Aeronautics and Space Database and its public interface, the NASA Technical Reports Server, thus providing one of the largest collections of aeronautical and space science STI in the world. Results are published in both non-NASA channels and by NASA in the NASA STI Report Series, which includes the following report types:

- TECHNICAL PUBLICATION. Reports of completed research or a major significant phase of research that present the results of NASA programs and include extensive data or theoretical analysis. Includes compilations of significant scientific and technical data and information deemed to be of continuing reference value. NASA counterpart of peer-reviewed formal professional papers but has less stringent limitations on manuscript length and extent of graphic presentations.

- TECHNICAL MEMORANDUM. Scientific and technical findings that are preliminary or of specialized interest, e.g., quick release reports, working papers, and bibliographies that contain minimal annotation. Does not contain extensive analysis.

- CONTRACTOR REPORT. Scientific and technical findings by NASA-sponsored contractors and grantees.
- CONFERENCE PUBLICATION. Collected papers from scientific and technical conferences, symposia, seminars, or other meetings sponsored or cosponsored by NASA.

- SPECIAL PUBLICATION. Scientific, technical, or historical information from NASA programs, projects, and missions, often concerned with subjects having substantial public interest.

- TECHNICAL TRANSLATION. Englishlanguage translations of foreign scientific and technical material pertinent to NASA's mission.

Specialized services also include creating custom thesauri, building customized databases, organizing and publishing research results.

For more information about the NASA STI program, see the following:

- Access the NASA STI program home page at http://www.sti.nasa.gov

- E-mail your question via the Internet to help@ sti.nasa.gov

- Fax your question to the NASA STI Help Desk at $443-757-5803$

- Telephone the NASA STI Help Desk at 443-757-5802

- Write to: NASA Center for AeroSpace Information (CASI) 7115 Standard Drive Hanover, MD 21076-1320 


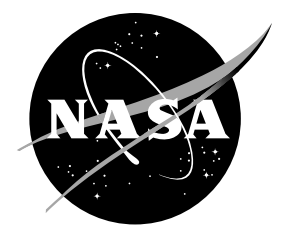

\section{Development of an Open Rotor Cycle Model in NPSS Using a Multi-Design Point Approach}

Eric S. Hendricks

Glenn Research Center, Cleveland, Ohio

Prepared for the

Turbo Expo 2011

sponsored by the American Society of Mechanical Engineers (ASME)

Vancouver, British Columbia, Canada, June 6-10, 2011

National Aeronautics and

Space Administration

Glenn Research Center

Cleveland, Ohio 44135 


\section{Acknowledgments}

The work presented in this paper was supported by the Subsonic Fixed Wing Project at NASA Glenn Research Center. Special thanks to Jeff Berton, Bill Haller, Justin Gray, and Scott Jones of the NASA Glenn Research Center as well as Dr. Dimitri Mavris, Dr. Jimmy Tai, Dr. Jeff Schutte, and Chris Perullo of the Aerospace Systems Design Laboratory at the Georgia Institute of Technology for their support and guidance in this research.

This report is a formal draft or working paper, intended to solicit comments and ideas from a technical peer group.

report contains preliminary findings, subject to revision as analysis proceeds.

This work was sponsored by the Fundamental Aeronautics Program at the NASA Glenn Research Center.

Level of Review: This material has been technically reviewed by technical management.

Available from

NASA Center for Aerospace Information 7115 Standard Drive Hanover, MD 21076-1320
National Technical Information Service 5301 Shawnee Road Alexandria, VA 22312 
Development of an Open Rotor Cycle Model in NPSS

Using a Multi-Design Point Approach

Eric S. Hendricks

National Aeronautics and Space Administration

Glenn Research Center

Cleveland, Ohio 44135

\begin{abstract}
NASA's Environmentally Responsible Aviation Project and Subsonic Fixed Wing Project are focused on developing concepts and technologies which may enable dramatic reductions to the environmental impact of future generation subsonic aircraft (Refs. 1 and 2). The open rotor concept (also referred to as the Unducted Fan or advanced turboprop) may allow the achievement of this objective by reducing engine emissions and fuel consumption. To evaluate its potential impact, an open rotor cycle modeling capability is needed. This paper presents the initial development of an open rotor cycle model in the Numerical Propulsion System Simulation (NPSS) computer program which can then be used to evaluate the potential benefit of this engine.

The development of this open rotor model necessitated addressing two modeling needs within NPSS. First, a method for evaluating the performance of counter-rotating propellers was needed. Therefore, a new counter-rotating propeller NPSS component was created. This component uses propeller performance maps developed from historic counter-rotating propeller experiments to determine the thrust delivered and power required. Second, several methods for modeling a counter-rotating power turbine within NPSS were explored. These techniques used several combinations of turbine components within NPSS to provide the necessary power to the propellers. Ultimately, a single turbine component with a conventional turbine map was selected.

Using these modeling enhancements, an open rotor cycle model was developed in NPSS using a multi-design point approach. The multi-design point (MDP) approach improves the engine cycle analysis process by making it easier to properly size the engine to meet a variety of thrust targets throughout the flight envelope. A number of design points are considered including an aerodynamic design point, sea-level static, takeoff and top of climb. The development of this MDP model was also enabled by the selection of a simple power management scheme
\end{abstract}

which schedules propeller blade angles with the freestream Mach number. Finally, sample open rotor performance results and areas for further model improvements are presented.

\section{Introduction}

Passenger travel by commercial aviation is expected to grow at a steady pace over the next 10 to 15 years (Refs. 3, 4, and 5). This expected increase in the number of passengers will place significant strain on the current air transportation system. In addition to creating more congestion and delays, the increase in air travel will amplify aviation's impact on the environment (Refs. 4, 6, and 7). Therefore, several of NASA's primary goals for the future are the significant reduction of aircraft fuel burn, community noise, emissions of nitrogen oxides (NOx) and field length for the next generation of commercial single aisle aircraft (Ref. 12). These aggressive goals are used to develop technology roadmaps and guide technology research efforts across a number of research disciplines.

A technology area of particular interest to NASA and the commercial aviation industry is that of advanced engine concepts (Ref. 8). One specific concept in this research area that is receiving considerable attention is the open rotor as it has the potential to dramatically reduce aircraft fuel consumption. The open rotor concept achieves these reductions by using a large, counterrotating advanced propeller as shown in Figure 1. The advanced counter-rotating propeller allows for many of the fuel efficiency benefits of a traditional turboprop to be achieved without the sacrifice of maximum aircraft speed typically required. The open rotor engine concept was originally developed during the 1980's under the NASA's Advanced Turboprop Project (Ref. 9), and demonstrated significant fuel burn reductions. However, due to reduced fuel prices and several technical challenges facing open rotor implementation, the concept was not developed further. 


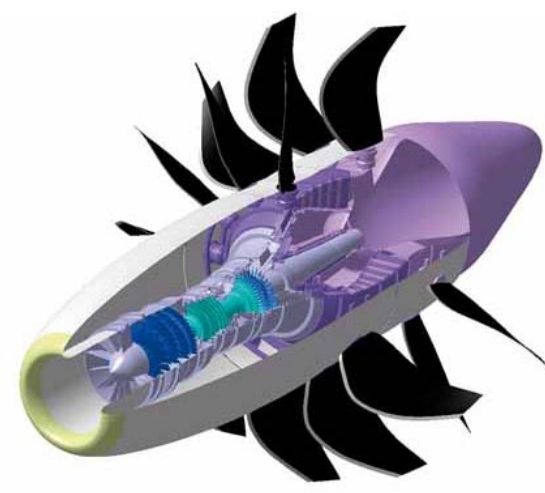

Figure 1.-Cutaway of a notional open rotor concept (Ref. 10).

While the open rotor engine developed during the Advanced Turboprop Project demonstrated significant reductions in fuel consumption, the lack of development over the last two decades has allowed conventional turbofans to close the performance gap (Refs. 9 and 11). However, many of the technological improvements which have been made to turbofans can also be applied the open rotor, thereby further improving its performance. In addition, advances in computing and design are enabling the creation of more advanced counter-rotating propeller blades. With these improvements to both conventional gas turbine components and counter-rotating propellers, there is a need to evaluate the potential improvements available in open rotor engines. The development of a new analytical cycle model is critical to the evaluation of conceptual open rotor aircraft designs such as those shown in Figure 2.

This paper summarizes the development of an open rotor engine cycle model with the NPSS computer program. NPSS is a variable-fidelity, object-oriented, engine cycle analysis tool developed jointly by NASA and U.S. industry (Refs. 12 and 13). It is currently the accepted, state-of-the-art software for airbreathing engine cycle performance analysis for U.S. aerospace industry, academia, and NASA. In the next few sections, the following topics related to the open rotor cycle model development will be addressed:

- Selection of an open rotor engine architecture and implementation in NPSS

- NPSS model enhancements for counter-rotating propeller performance prediction

- Potential solutions for estimating counter-rotating turbine performance in NPSS

- Implementation of a multi-design point formulation to improve process for creating candidate engine models

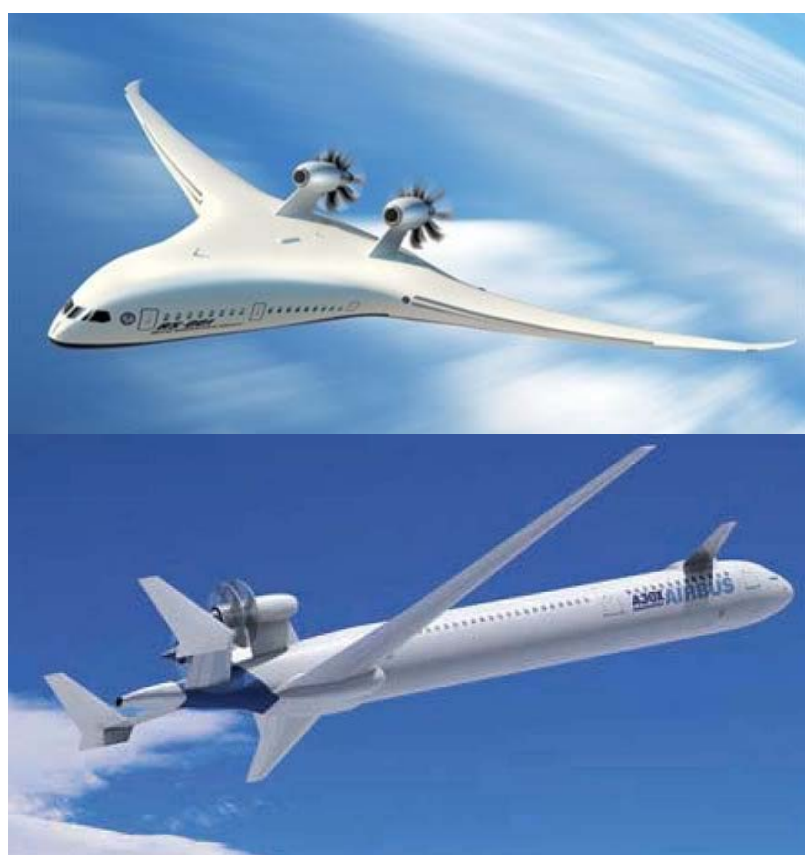

Figure 2.-Notional open rotor airplane concepts (Refs. 14 and 15)

- Determination of a power management strategy allowing for performance estimation throughout the flight envelope

- Presentation of sample engine performance results

- Areas for further model improvements

\section{Nomenclature}

A

ADP

Alt

$\beta$

$\mathrm{C}_{\mathrm{P}}$

$\mathrm{C}_{\mathrm{T}}$

$\mathrm{D}$

ENET

$\mathrm{F}_{\mathrm{g}}$

FAR

$\Delta \mathrm{h}$

HP

HPC

HPT

ISA

$\mathrm{J}$ (or J1C)

LP

LPC

LPT
Propeller Annulus Area

Aerodynamic Design Point

Altitude

Front Blade angle

Net Power Coefficient, $\mathrm{P} / \mathrm{\rho n}^{3} \mathrm{D}^{5}$

Thrust Coefficient, $\mathrm{F}_{\mathrm{g}} / \mathrm{\rho n}^{2} \mathrm{D}^{4}$

Diameter

Net Propeller Efficiency, $\mathrm{J} \mathrm{C}_{\mathrm{T}} / \mathrm{C}_{\mathrm{P}}$

Propeller Gross Thrust

Fuel to Air Ratio

Specific Enthalpy Change

High Pressure

High Pressure Compressor

High Pressure Turbine

International Standard Atmosphere

Front Rotor Advance Ratio, V/nD

Low Pressure

Low Pressure Compressor

Low Pressure Turbine 


$\begin{array}{ll}\text { M } & \text { Mach Number } \\ \text { MDP } & \text { Multi-Design Point } \\ \text { N, n } & \text { Rotation Speed } \\ \text { NPSS } & \text { Numerical Propulsion System Simulation } \\ \text { PQA } & \text { Modified Power Coefficient, } \mathrm{P} / \mathrm{\rho n}^{3} \mathrm{D}^{3} \mathrm{~A} \\ \text { PQAJ3 } & \text { Modified Power Coefficient divided by } \\ & \text { Advance Ratio cubed } \\ \text { PT } & \text { Power Turbine } \\ \text { SLS } & \text { Sea-Level Static } \\ \text { T } & \text { Temperature } \\ \text { T4 } & \text { Combustor Exit Temperature } \\ \text { TO } & \text { Takeoff } \\ \text { TOC } & \text { Top of Climb } \\ \text { TSFC } & \text { Thrust Specific Fuel Consumption } \\ \text { TQA } & \text { Modified Thrust Coefficient, } \mathrm{F}_{\mathrm{g}} / \mathrm{\rho n}^{2} \mathrm{D}^{2} \mathrm{~A} \\ \text { UDF } & \text { Unducted Fan }\end{array}$

\section{NPSS Open Rotor Model Development}

The first task in developing an open rotor engine model was selecting an engine architecture. Several different architectures for the open rotor engine have been proposed which include variations in the location of the propellers (pusher vs. tractor), number of shafts, gearboxes and turbine design, among other parameters. For this study, a gearless, pusher engine configuration similar to the GE36 Unducted Fan (UDF) shown in Figure 3 was chosen for the initial open rotor model development. In this architecture, the engine can be split into two distinct sections: the gas generator and propulsor. The gas generator is comprised of the low and high pressure spools and combustor (in the GE36, the gas generator was an F404). The propulsor section contains the counter-rotating propellers which are driven by the counter-rotating power turbine and the exhaust nozzle. It is important to note that these two sections are mechanically independent (no shaft connections between sections), but are aerodynamically linked by the core engine flow.

With this architecture selected, an engine model could be developed in NPSS. The engine was decomposed into a series of components as shown in Figure 4. Most of the blocks shown in Figure 4 are blue as NPSS already contains analysis capabilities for these components. The green blocks, however, identify two unique engine components which were not readily available in NPSS. As a result, solutions needed to be identified for how to model the counter-rotating propeller and counter-rotating turbine within NPSS. The next two sections will describe the steps taken to estimate the performance of the counter-rotating propellers and turbine using available performance data.

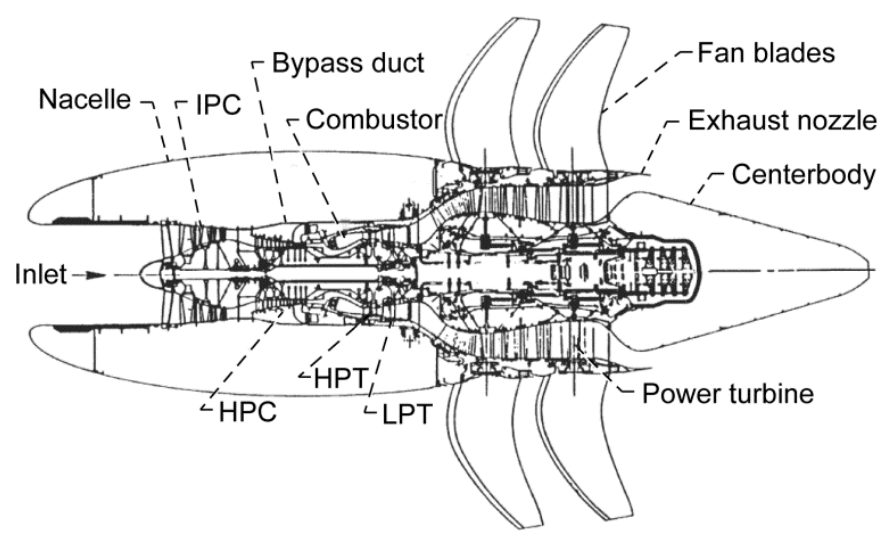

Figure 3.-GE36 UDF cross section (Ref. 16).

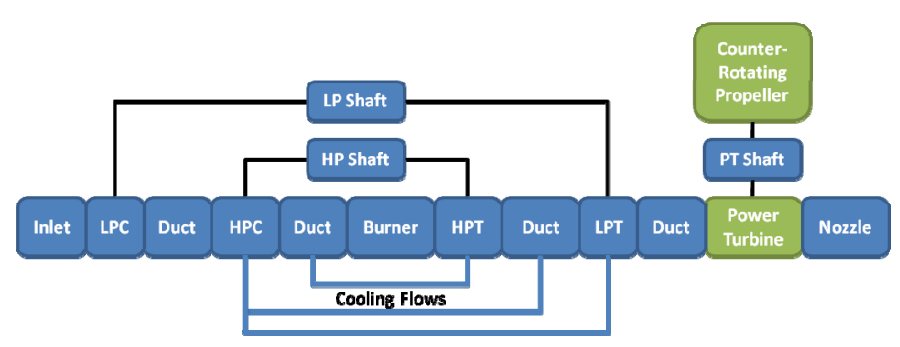

Figure 4.-Open rotor block diagram.

\section{Counter-Rotating Propeller Modeling}

Several open rotor propeller configurations were designed, built, and tested as part of the Advanced Turboprop Project. These configurations were designed for optimal operation at different Mach numbers and had different blade geometries. Of all the blade geometries designed and tested, the most thoroughly documented was the F7/A7 rotor set. These propellers were designed for Mach 0.72 operation and were used on the GE36 UDF demonstrator. Because of available data, the F7/A7 configuration was selected to provide an initial estimate of future open rotor propeller performance for this study.

The performance data reported for the F7/A7 was from wind tunnel tests and was presented as shown in Figure 5. In the top plot, the modified total power coefficient (PQA) is shown as a function of the front propeller advance ratio (J1C) and propeller blade angles (each line represents a single combination of front and aft blade angles). In the bottom plot, the net efficiency of the counter-rotating propellers is shown as a function of the power coefficient divided by advance ratio, cubed (PQAJ3) and propeller blade angles. Plots such as these were given as several different Mach numbers to describe the semi-installed performance (the effects of the upstream nacelle are captured, but not an upstream pylon) at several points throughout the flight envelope (Ref. 17). 

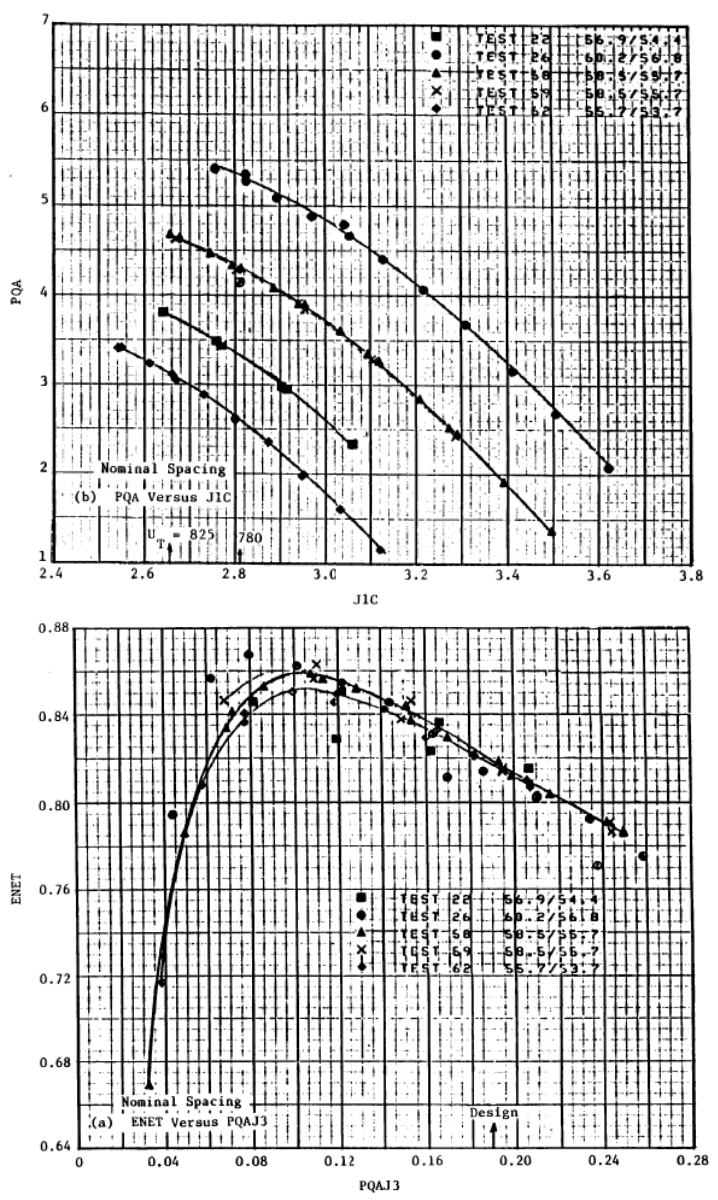

Figure 5.-F7/A7 propeller performance data at Mach 0.72 (Ref. 17).

In addition, limited data were provided describing the distribution of torque between the blade rows at several flight conditions and blade angles.

Using the reported data, counter-rotating performance maps were created for use in the cycle model. These maps contain correlations to determine the thrust coefficient, power coefficient and power split between the propeller blade rows as functions of Mach number, advance ratio and front propeller blade angle. Traditional NPSS performance maps capture these relationships in multidimensional arrays which are then interpolated or extrapolated for points not contained in the table. This technique was initially used in the open rotor modeling process by creating arrays based on the data reported from the F7/A7 wind tunnel experiments. However, because of the sparse data provided for the F7/A7, extensive extrapolation was required for many flight conditions. In this extrapolation process, the values of thrust and power coefficient calculated often produced unreasonable estimates of propeller efficiency.
In order to improve the estimation of the thrust coefficient, power coefficient and efficiency at extrapolated points, the tables were replaced with response surface equations (multi-variable regression equations) which relate performance to Mach number, advance ratio and blade angle. These equations better capture the trends in the data in comparison to interpolating and extrapolating based on tables. Therefore, a set of response surface equations fit to the F7/A7 performance data were developed for use in this model and are provided in the Appendix.

With the propeller performance data captured in the maps, a counter-rotating propeller element was written for NPSS which computes the performance of counterrotating propellers as engine components. The NPSS counter-rotating propeller element has a fluid input port and fluid output port along with a shaft port for each blade row. When the engine is being evaluated in design mode, the design blade angle and the propeller diameter are determined based on the specified total power requirements, rotation speed and disk loading. In offdesign mode, the propeller power required and thrust produced are determined from input flight conditions, rotation speed and blade angles.

\section{Counter-Rotating Turbine Modeling}

One of the challenges associated with modeling this open rotor configuration is the counter-rotating turbine which drives the propellers. A notional schematic of the counter-rotating turbine and propellers as used in the GE36 UDF is shown in Figure 6. In this configuration, the only static blade rows are the inlet and exit guide vanes. The remaining blade rows in the power turbine all rotate, with odd and even numbered rows rotating in opposite directions. This can been seen in Figure 6 as the solid blade rows will rotate in one direction, while the hatched blade rows will spin in the opposite direction. This configuration is unique resulting in little historic data and analytical analysis capabilities existing for this type of turbine. A partial performance map for the GE36 counter-rotating power turbine was found as shown in Figure 7 giving some insight into the performance. However, this overall power turbine map does not include information on turbine pressure ratio and mass flow limiting its utility. An additional limitation of the map is that it is applicable only when there are equal rotation speeds for the two propulsor shafts. This lack of data and analysis capabilities make it difficult to model the counter-rotating turbine in NPSS, requiring exploration of 


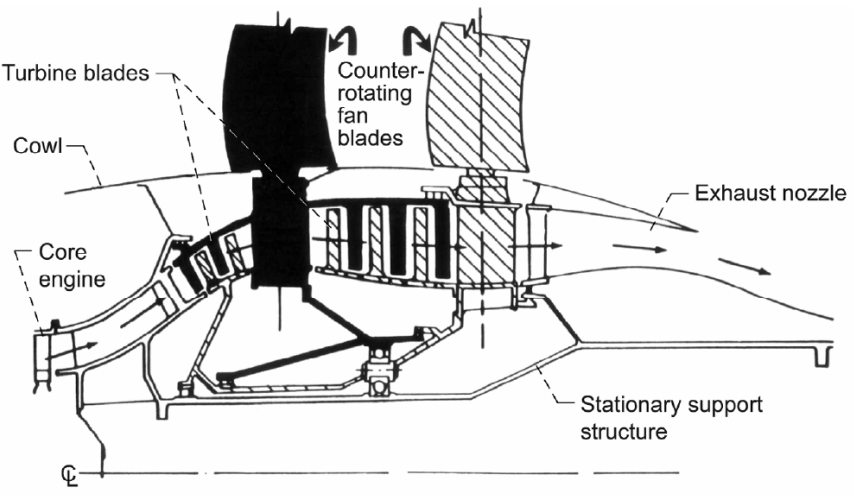

Figure 6.-Schematic of GE36 Power Turbine (Ref. 18).

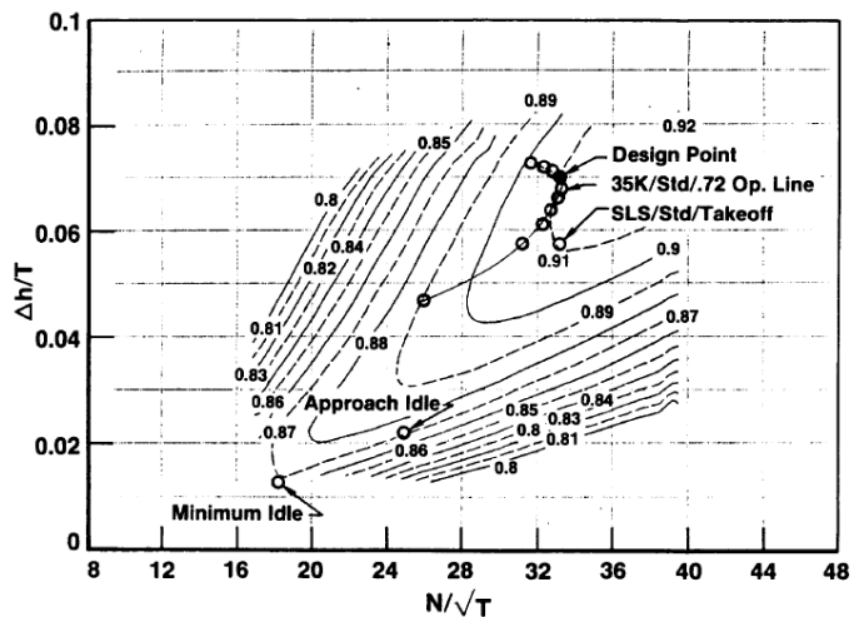

Figure 7.-GE36 Overall Power Turbine Performance Map (Ref. 19).

several counter-rotating turbine performance estimation techniques.

The first technique examined focused on trying to match what would be physically occurring in the counterrotating turbine. Specifically, it was assumed that the work being extracted in an alternating fashion for the two propulsor shafts was an important characteristic to capture. Therefore, a blade row by blade row model was implemented in NPSS by placing 12 turbine elements (the same as the number of blade rows in the GE36) in series and linking their flow ports. These twelve turbines were then linked alternately linked to two shaft elements. This turbine setup required several additional parameters to implement properly. During design, the work distribution across the 12 stages needed to be specified and was set to values similar to those described in the GE36 Design Report (Ref. 19). Furthermore, the performance of each blade row at all operating conditions needed to be estimated and was done by applying a performance map for a traditional, single stage turbine to each blade row. The performance maps of each blade row were then scaled such that the desired total power turbine adiabatic efficiency was achieved providing similar performance to the GE36 power turbine (Ref. 19).

The results of implementing this power turbine modeling method were mixed. In the region near the design turbine design point, the total turbine performance map generated by the blade row by blade row model provided efficiency contours of similar shape to those shown in Figure 7. However, at off-design cases farther away from the design point the quality of this modeling approach deteriorated as the model often would not converge or would converge on a physically infeasible solution. The most common observation was that the last blade row in the power turbine would act as a compressor, absorbing power and raising the pressure across the row. The precise cause of this numerical phenomenon has not been determined, but there are several possible factors that may be contributing. First, the performance maps used for each blade row did not capture changes to inflow swirl from the preceding stage. Therefore, changes to performance from variations in rotation speeds of both shafts were not captured. Second, the work extraction distribution across the stages which was specified at design may be incorrect, resulting in too little energy being available in the last stages of the turbine. Finally, the power split determined in the counter-rotating propeller map (which is based on sparse data) may be driving the solution to an unrealistic result. Due to these results, the blade row by blade row power turbine model was not pursued further, but may be considered again in the future.

Next, two simplified power turbine models were considered. First, the power turbine was modeled using two conventional turbine components in series. This modeling approach eliminates the single blade row map and work extraction issues of the blade row by blade row model while still allowing both propellers to be driven independently. However, the implementation of this method in NPSS still did not produce acceptable offdesign performance. These results indicate that there is likely an interaction between the counter-rotating propeller and power turbine which is not correctly addressed with both this method and the blade row by blade row turbine model.

Finally, a single, traditional, low pressure turbine NPSS element was used to drive the entire counterrotating propeller system. This method assumes that only the total power passed between the power turbine and propellers is important (it does not take into account the power split between the rotors). The method also forces the rotation speed of the propellers to be equal. Therefore, 
the single NPSS component power turbine model was implemented in the NPSS open rotor model. This technique was also selected by Bellocq et al. in their study of open rotor performance modeling (Ref. 20).

\section{Multiple-Design Point Formulation}

Through the development of the counter-rotating propeller and turbine modeling capabilities in NPSS, a complete NPSS model of an open rotor turbine engine model was constructed following the block diagram of Figure 4. While this block diagram details the layout of components within the engine, it does not describe the process which will be used to size the engine to meet various performance requirements throughout the flight envelope. The traditional engine cycle design process uses a single design point (cruise or takeoff) to size the engine. The off-design performance is then evaluated to determine if thrust targets are met at other flight conditions. If thrust targets are not met at these other flight conditions, the engineer must manually change parameters at the design point until all the thrust targets are met. This process can be quite tedious, especially for unconventional engines such as the open rotor where the engineer has little intuition regarding the effect of changing design point variables.

In order to improve the process of sizing the open rotor engine to meet multiple thrust targets, the open rotor model is being implemented using a multiple-design point formulation. In this formulation, the NPSS model is constructed so that all critical flight conditions are evaluated simultaneously to ensure all thrust targets and other design requirements are met. Therefore, each designed engine is guaranteed to meet the performance requirements specified by the designer. This technique was proposed and evaluated in academia for NPSS by Schutte (Ref. 21) and is capable of handling a larger number of design points. The rest of this section will describe some of the details regarding the implementation of the open rotor in an MDP formulation.

First, the design points and their associated thrust targets need to be identified. For a typical engine, several design points including top-of-climb, takeoff and sealevel static are often considered. Table 1 lists several example design points which were considered in the development of this open rotor model. The aerodynamic design point (ADP) refers to a throttled back operating point representative of a cruise condition where the turbomachinery components would be designed for best
TABLE 1.-DESIGN POINTS FOR MDP FORMULATION

\begin{tabular}{|l|c|r|c|c|}
\hline Design point & Mach & Alt (ft) & $\begin{array}{c}\Delta \mathrm{T}\left({ }^{\circ} \mathrm{F}\right) \\
(\text { from ISA) }\end{array}$ & $\begin{array}{c}\text { Net thrust } \\
(\mathrm{lbf})\end{array}$ \\
\hline ADP & 0.72 & 35,000 & +0 & $\mathrm{n} / \mathrm{a}$ \\
\hline TOC & 0.72 & 35,000 & +0 & 4,600 \\
\hline TO, Hot Day & 0.25 & 0 & +27 & 17,500 \\
\hline SLS, Hot Day & 0.00 & 0 & +27 & 25,000 \\
\hline
\end{tabular}

TABLE 2.-NPSS SOLVER VARIABLES FOR MDP FORMULATION

\begin{tabular}{|l|l|}
\hline \multicolumn{1}{|c|}{ NPSS Independent } & \multicolumn{1}{c|}{ NPSS Dependent } \\
\hline TOC Core Mass Flow & TO Net Thrust \\
\hline TOC FAR & TOC Net Thrust \\
\hline TO FAR & TO T4 Max \\
\hline TOC Propeller Power & TOC Nozzle Pressure Ratio \\
\hline TOC Propulsor Speed & TOC Propeller Tip Speed \\
\hline
\end{tabular}

performance. For example, this would be the flight condition and throttle setting at which the propellers were designed.

From the list provided in Table 1, two design points were selected for the current study: top-of-climb and hot day takeoff. These two points were selected as they were the two primary thrust targets for this engine. There was not enough information available regarding the throttled back cruise condition to define an aerodynamic design point; therefore, the TOC point was used as the ADP of the turbomachinery components. Using these two design points, the MDP model was constructed by adding the parameters in Table 2 to the NPSS solver. Of these five independent/dependent pairs, the first three allow the sizing of the engine for matching the thrust targets at both TOC and TO. The last two independents and dependents size the propeller in relation to the gas generator at TOC and ensure that the F7/A7 design characteristics are matched.

Within the NPSS, the solver is varying these independent parameters in order to achieve specific values of the dependent variables at the appropriate flight conditions (in addition to other independents and dependents automatically added to the solver). Therefore, target values for each dependent must be specified. For the first three dependents, the target values are determined by the thrust requirements and technology assumptions being used by the designer. The propeller tip speed target is determined from the propeller design process. For the F7/A7, the design front propeller tangential tip speed was 780 feet per second. Finally, the core nozzle pressure ratio must be specified as it determines the relative size of counter-rotating propellers and core engine. For this study a nozzle pressure ratio of 1.25 was selected at TOC. By selecting this value for 
nozzle pressure ratio, almost all the energy is being extracted from the core flow to drive the counter-rotating propellers. Therefore, almost all the thrust is being produced by the high efficiency propellers, lowering the engine TSFC. While this value for nozzle pressure ratio is low at the TOC design point, it allows enough margin so that the pressure ratio remains above unity throughout the flight envelope.

\section{Power Management Strategy}

Another challenge in developing the open rotor MDP model was selecting a method for controlling the engine at each operating point in the flight envelope. The control of the open rotor engine differs from a traditional turbofan because both the propeller blade angle and combustor fuel flow can be varied. Therefore, a strategy for controlling both of these parameters throughout the flight envelope was required to allow for the proper sizing of engine in the MDP and estimation of performance in off-design operation.

In order to develop the proper power management strategy, several brief studies were conducted to determine relevant trends in the engine operation. Figure 8 below shows a powerhook for the engine at cruise with three different blade angles. The figure shows that for all three blade angles, the powerhooks are nearly identical for most of the operating range. The significant difference occurs at the maximum thrust setting for each blade angle. The maximum thrust for each blade angle differs as a result of other constraints on the engine operation such as the maximum combustor exit temperature, maximum LPC corrected speed and maximum propeller rotation speed. Similar trends are observed at takeoff conditions as shown in Figure 9.

Using the results of these studies, a simple blade angle schedule was selected as shown by the green line in

Figure 10. This characteristic was selected as it passes through the known F7/A7 design point and falls within the bounds of the reported experimental data at all Mach numbers. By selecting a single front propeller blade angle at each Mach number, a reasonable prediction of the conceptual open rotor performance can be obtained throughout the flight envelope. It is recognized that the schedule selected in Figure 10 will provide a conservative estimate of the maximum thrust available as seen in Figure 8 and Figure 9. Following the development of this schedule, additional data which covers a larger range of Mach numbers was found for the F4/A4 and F5/A5 open

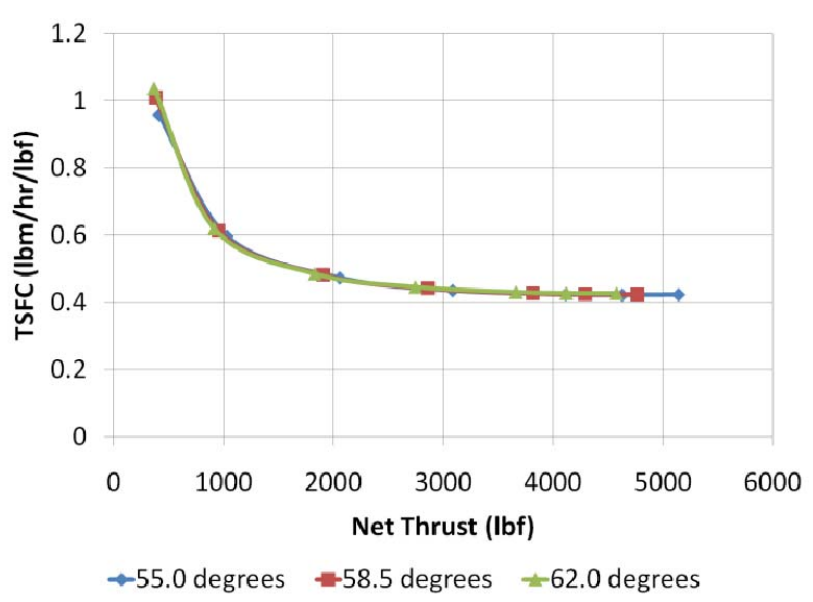

Figure 8.-Mach $0.72,35 \mathrm{kft}$ powerhooks.

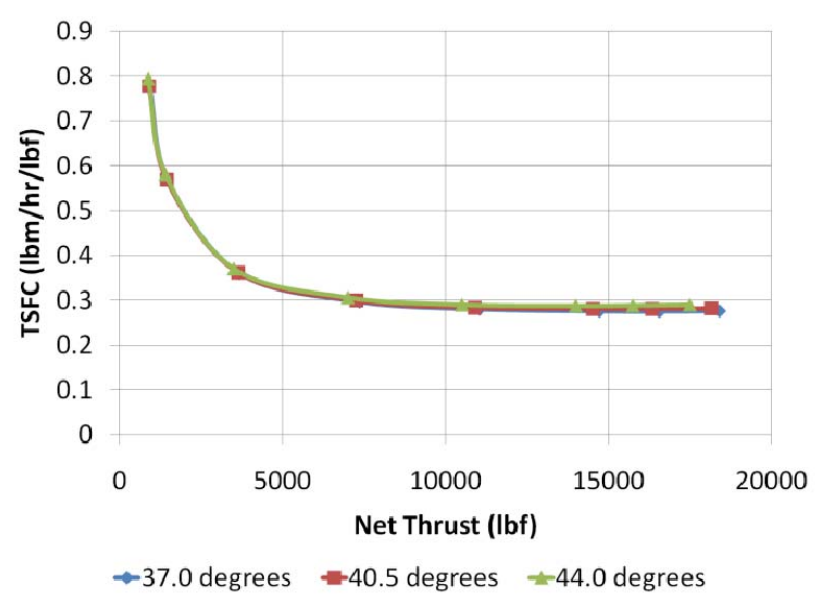

Figure 9.-Mach 0.25, sea-level powerhooks.

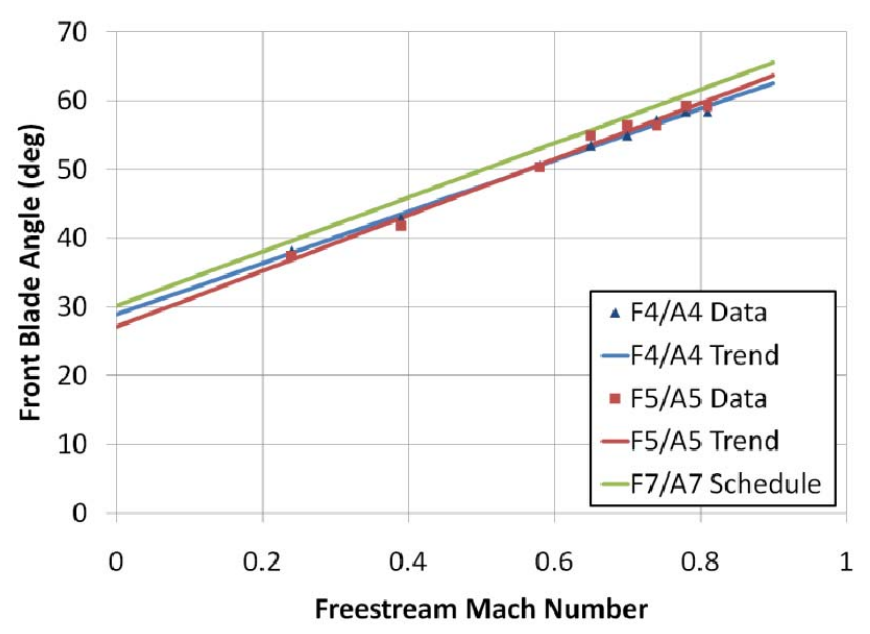

Figure 10.-Front propeller blade angle schedule. 
rotor blade sets. These blade sets were developed around the same time as the F7/A7 for a similar cruise Mach number, but had different blade geometry (Ref. 17). While this data was not reported in the context of a power management strategy, the front blade angle of both blade sets follows a linear trend similar to that selected for the F7/A7, supporting the use of this schedule for preliminary performance evaluation. Future refinement of this schedule may allow for improved prediction of maximum thrust at each flight condition.

Several other options for developing a power management scheme have also been considered which would provide more complex control of blade angle and fuel flow. One option is to use an optimizer to select the blade angle resulting in the minimum TSFC at a given T4. The advantage of this technique is that it would allow for the proper blade angle at every point analyzed and the scheme would be rapidly adjustable to new designs. However, the inclusion of an optimizer in NPSS model substantially lengthens the execution time and often results in numerical stability problems. Other power management schemes are also being investigated based on more detailed studies of the operating characteristics of the engine. In this case, it may be possible to use the identified characteristics in conjunction with the NPSS solver to select the appropriate blade angle and fuel flow settings. The difficultly observed with this method to date is the operating characteristics of the engine do not appear to be consistent throughout the flight envelope making it difficult to set up the proper NPSS solver variables.

\section{Sample Performance Results}

The open rotor modeling enhancements described in the previous sections were used to construct a complete NPSS model of the gearless, pusher engine. The model uses the F7/A7 counter-rotating propeller driven by a single power turbine component. The MDP setup contains only TOC and TO points with the blade angle determined by the simple schedule presented above.

Using the developed model, a notional open rotor engine was created for evaluation. The results presented in this section are examples intended to demonstrate the capabilities of the model and results which can be produced. A summary of the open rotor engine cycle parameters used to generate the sample results is provided in Table 3. Values for core component design parameters were selected to represent advanced technology levels while power turbine and counter-rotating propellers parameters were selected to represent expected improvements over the GE36 Unducted Fan.
Evaluating the open rotor NPSS model with these inputs produces the results given in Table 4 . While this engine was not designed to exactly match the GE36, it is comparable in the overall size and thrust as shown in Table 5. The sample engine presented here has a slightly smaller propeller diameter and SLS thrust. However, it also demonstrates a lower TSFC due to the utilization of a modern gas generator. In addition, further improvements in the TSFC of the sample open rotor may be possible with further design and optimization.

TABLE 3.-CYCLE DEFINITION AT TOC (* AT TO)

\begin{tabular}{|l|l|l|}
\hline Component & \multicolumn{1}{|c|}{ Parameter } & Value \\
\hline \multirow{2}{*}{ LPC } & Pressure Ratio & 2.4 \\
\cline { 2 - 3 } & Adiabatic Efficiency (\%) & 87.6 \\
\hline \multirow{2}{*}{ HPC } & Pressure Ratio & 17.7 \\
\cline { 2 - 3 } & Adiabatic Efficiency (\%) & 87.8 \\
\hline Burner & Exit Temperature ( $\left.{ }^{\circ} \mathrm{R}\right) *$ & 3460 \\
\hline HPT & Adiabatic Efficiency (\%) & 92.1 \\
\hline LPT & Adiabatic Efficiency (\%) & 94.1 \\
\hline PT & Adiabatic Efficiency (\%) & 92.0 \\
\hline \multirow{2}{*}{$\begin{array}{l}\text { Counter- } \\
\text { Rotating } \\
\text { Propellers }\end{array}$} & Net Efficiency $(\%)$ & 85.0 \\
\cline { 2 - 3 } & Front Tip Speed $(\mathrm{ft} / \mathrm{s})$ & 780 \\
\cline { 2 - 3 } & Power Loading $\left(\mathrm{shp} / \mathrm{D}^{2}\right)$ & 55.5 \\
\hline
\end{tabular}

TABLE 4.-OPEN ROTOR CYCLE RESULTS

\begin{tabular}{|l|c|}
\hline \multicolumn{1}{|c|}{ Parameter (units) } & Value \\
\hline Front Propeller Diameter (ft) & 10.9 \\
\hline TOC Core Mass Flow (lbm/s) & 19.6 \\
\hline TOC Net Thrust (lbf) & 4600 \\
\hline TOC Propeller Thrust (lbf) & 4410 \\
\hline TOC TSFC (lbm/hr/lbf) & 0.394 \\
\hline TO Core Mass Flow (lbm/s) & 43.8 \\
\hline TO Net Thrust (lbf) & 17,500 \\
\hline TO Propeller Thrust (lbf) & 16,966 \\
\hline TO TSFC (lbm/hr/lbf) & 0.25 \\
\hline
\end{tabular}

TABLE 5.-SAMPLE OPEN ROTOR AND GE36 DESIGN CHARACTERISTICS (REF. 9)

\begin{tabular}{|l|c|c|}
\hline \multicolumn{1}{|c|}{ Parameter (units) } & $\begin{array}{c}\text { Sample } \\
\text { Open } \\
\text { Rotor }\end{array}$ & $\begin{array}{c}\text { GE36 } \\
\text { Unducted } \\
\text { Fan }\end{array}$ \\
\hline Propeller Diameter (ft) & 10.9 & 11.7 \\
\hline OPR & 42 & 27 \\
\hline SLS Thrust (lbf) & 22,119 & 25,000 \\
\hline TSFC, M 0.8, 35,000 ft $(\mathrm{lbm} / \mathrm{hr} / \mathrm{lbf})$ & 0.45 & 0.52 \\
\hline
\end{tabular}




\section{Conclusion and Future Work}

The renewed interest in open rotor aircraft engines due to their capacity to reduce fuel consumption has necessitated the development of open rotor cycle models. In order to develop such models within NPSS, several modeling enhancements were needed to provide analysis capabilities for counter-rotating propellers and turbines. In addition, the implementation of a multi-design point methodology and a simple power management scheme allow for rapid cycle design and exploration of the entire flight envelope.

While this work has provided a step forward in open rotor cycle analysis capabilities, there still remains room for dramatic improvement in open rotor modeling and analysis. First, the model presented here is based on a limited amount of historic, publicly available counterrotating propeller performance data. Several engine companies are currently designing and testing new propeller designs. If these performance data are made available, the data can be converted into performance maps and used in the cycle model. Additionally, if analytical counter-rotating propeller performance codes are developed or identified, it may be possible to integrate (i.e., "wrap") them into the NPSS framework so that new propeller designs can be evaluated. By implementing an analytical propeller performance code, a more detailed understanding of counter-rotating propeller performance and its impact on the cycle design could be achieved.

Next, further investigation regarding counter-rotating turbine performance estimation is needed. While the current model using a single turbine element will provide reasonable performance estimates for conceptual design, it does not allow for more detailed studies of open rotor design. A more complete theoretical understanding of counter-rotating turbine performance needs to be established which will lead to a sophisticated counterrotating turbine model within NPSS. By improving the turbine and propeller models, a better understanding will be developed regarding the interaction and coupling of these components and the limits those effects place on the design of such systems.

Finally, if improved models for the counter-rotating propellers and turbines are implemented, the power management scheme will need to be reevaluated. This will be especially necessary if the new models demonstrate a high degree of coupling between the two systems as the performance characteristics may change.

The development of the new capabilities described in this paper will make possible future open rotor cycle studies and aircraft design studies. NASA is interested in evaluating several different open rotor configurations, specifically tractor/pusher and geared/ungeared variations. Many of the developments described in this paper, including the propeller performance modeling, multidesign point sizing and power management strategy, will be applicable to the modeling of all these open rotor engine architectures. The evaluation of these open rotor configurations will also be conducted at the vehicle level so that a meaningful comparison can carried out between open rotors, high-bypass ratio turbofans and geared turbofan engines. 



\section{Appendix-Counter-Rotating Propeller Response Surface Equations}

Thrust coefficient for cruise Mach numbers:

$C_{T}=0.477858888468182+7.06020237179521 \times M+0.106298212735099 \times \beta-4.2264950825376 \times J$ $-3.66227236419897 \times M^{2}-0.135610213199312 \times M \times \beta-0.000855628477643638 \times \beta^{2}$

$+1.56685453798423 \times M \times J+0.0712347127445022 \times \beta \times J-0.315151540318393 \times J^{2}$

Thrust coefficient for takeoff Mach numbers:

$C_{T}=-2.82997954389849+0.180742434146289 \times \beta-1.1579348683331 \times J+0.0158989848771736 \times \beta$ $\times J-0.158269167605173 \times J^{2}-0.00172659713577937 \times \beta^{2}$

Power coefficient for cruise Mach numbers:

$C_{P}=19.799023228925+18.4702389814161 \times M-0.590047973770211 \times \beta-9.99634088349976 \times J$ $-10.0200863814251 \times M^{2}-0.367383133097003 \times M \times \beta+0.00635741314998766 \times \beta^{2}$ $+4.60880216127912 \times M \times J+0.185060516036581 \times \beta \times J-1.08805807929953 \times J^{2}$

Power coefficient for takeoff Mach numbers:

$C_{P}=-3.87744594552613+0.167892520010464 \times \beta-0.0438743949610855 \times J-0.0215083034537208$ $\times \beta \times J-0.237242660435654 \times J^{2}$ 



\section{References}

1. National Aeronautics and Space Administration. Subsonic Fixed Wing - Research Overview. 2009. $<\mathrm{http}: / /$ www.aeronautics.nasa.gov/fap/sfw_research overview_feature.html>. Accessed 26 Oct 2010.

2. Collier, F., Overview of NASA's Environmentally Responsible Aviation (ERA) Project. < http://www.aeronautics.nasa.gov/pdf/asm_2010_coll ier_508.pdf $>$. Accessed 2 Nov 2010.

3. Boeing. Current Market Outlook 2010-2029. $<\mathrm{http}$ //www.boeing.com/commercial/cmo/pdf/ Boeing_Current_Market_Outlook_2010_to_2029.pd f> Accessed 1 Nov 2010.

4. Federal Aviation Administration, FAA Flight Plan 2009-2013,2008. <http://www.faa.gov/about/ plans_reports/media/flight_plan_2009-2013.pdf $>$. Accessed 1 Nov 2010.

5. Federal Aviation Administration, Capacity Needs in the National Airspace System 2007-2025, 2007. $<$ http://www.faa.gov/airports/resources/publications/ reports/media/fact_2.pdf $>$. Accessed 1 Nov 2010.

6. Luther, L., Environmental impacts of airport operations, maintenance, and expansion, Congressional Research Service, RL 33949, April 2007. <http://www.policyarchive.org/handle/10207/ bitstreams/3205.pdf>. Accessed 11 Nov 2010.

7. United States Environmental Protection Agency, Evaluation of Air Pollutant Emissions from Subsonic Commercial Jet Aircraft, EPA420-R-99-013, 1999.

8. National Aeronautics and Space Administration. Subsonic Fixed Wing - Energy Efficiency. 2009. <

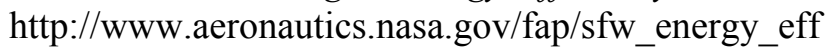
iciency.html>. Accessed 26 Oct 2010.

9. Hager, R. D. and Vrabel, D. Advanced Turboprop Project. NASA-SP-495. 1988.

10. Flight Global. Web. 26 Oct 2010. $<$ http://www.flightglobal.com/blogs/runwaygirl/2008/03/engine-rd-boost-begs-political1.html\#more>.
11. Guynn, M.D., Berton, J.J., Fisher, K.L., Haller, W.J., Tong, M.T., and Thurman, D.R. "Engine Concept Study for an Advanced Single-Aisle Transport." NASA-TM-2009-215784.

12. Claus, R.W.; Evans, A.L.; Lytle, J.K., and Nichols, L.D.: "Numerical Propulsion System Simulation," Computing Systems in Engineering, Vol. 2, No. 4, pp. 357-364, 1991.

13. NPSS User Guide Software Release: NPSS_1.6.5.

14. http://sitelife.aviationweek.com/ver1.0/Content/imag es/store/11/14/2b30674c-cd2f-47ae-be6363bf3434132f.Large.jpg

15. Airbus, Global Market Forecast 2009-2028. $<$ http://www.airbus.com/en/gmf2009/>.

16. GE Aircraft Engines, "Full Scale Technology Demonstration of a Modern Counterrotating Unducted Fan Engine Concept: Component Test." NASA-CR-180868. Dec. 1987.

17. Hoff, G.E. et al., "Experimental Performance and Acoustic Investigation of Modern, Counterrotating Blade Concepts." NASA-CR-185158. Jan. 1990.

18. Reid, C. "Overview of Flight Testing of GE Aircraft Engines UDF Engine." AIAA-88-3082.

19. GE Aircraft Engines, "Full Scale Technology Demonstration of a Modern Counterrotating Unducted Fan Engine Concept: Design Report." NASA-CR-180867. Dec. 1987.

20. Bellocq, P., Sethi, V., Cerasi, L., Ahlefelder, S., Singh, R., and Tantot, N., "Advanced Open Rotor Performance Modeling for Multidisciplinary Optimization Assessments." Proceedings of GT2010, ASME Turbo Expo 2010: Power for Land, Sea and Air, 2010, Glasgow, UK. Paper: GT201022963.

21. Schutte, Jeffrey S. Simultaneous Multi-design Point Approach to Gas Turbine On-design Cycle Analysis for Aircraft Engines. Atlanta, Ga.: Georgia Institute of Technology, 2009. 


\begin{tabular}{|c|c|c|}
\hline \multicolumn{2}{|c|}{ REPORT DOCUMENTATION PAGE } & $\begin{array}{l}\text { Form Approved } \\
\text { OMB No. 0704-0188 }\end{array}$ \\
\hline \multicolumn{3}{|c|}{ 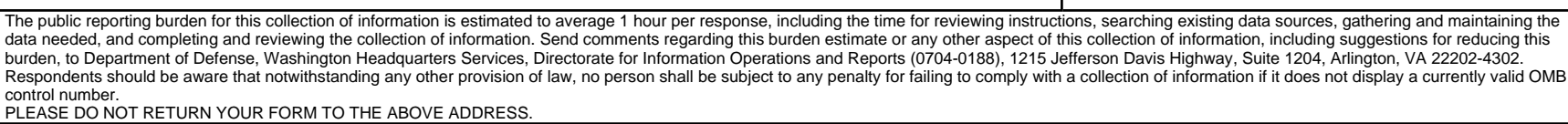 } \\
\hline $\begin{array}{l}\text { 1. REPORT DATE (DD-MM-YYYY) } \\
01-10-2011\end{array}$ & $\begin{array}{l}\text { 2. REPORT TYPE } \\
\text { Technical Memorandum }\end{array}$ & 3. DATES COVERED (From - To) \\
\hline \multirow{3}{*}{\multicolumn{2}{|c|}{$\begin{array}{l}\text { 4. TITLE AND SUBTITLE } \\
\text { Development of an Open Rotor Cycle Model in NPSS Using a Mult }\end{array}$}} & 5a. CONTRACT NUMBER \\
\hline & & 5b. GRANT NUMBER \\
\hline & & 5c. PROGRAM ELEMENT NUMBER \\
\hline \multirow{3}{*}{\multicolumn{2}{|c|}{$\begin{array}{l}\text { 6. AUTHOR(S) } \\
\text { Hendricks, Eric, S. }\end{array}$}} & 5d. PROJECT NUMBER \\
\hline & & 5e. TASK NUMBER \\
\hline & & $\begin{array}{l}\text { 5f. WORK UNIT NUMBER } \\
\text { WBS 561581.02.08.03.13.11 }\end{array}$ \\
\hline \multicolumn{2}{|c|}{$\begin{array}{l}\text { 7. PERFORMING ORGANIZATION NAME(S) AND ADDRESS(ES) } \\
\text { National Aeronautics and Space Administration } \\
\text { John H. Glenn Research Center at Lewis Field } \\
\text { Cleveland, Ohio 44135-3191 }\end{array}$} & $\begin{array}{l}\text { 8. PERFORMING ORGANIZATION } \\
\text { REPORT NUMBER } \\
\text { E-17908 }\end{array}$ \\
\hline \multirow{2}{*}{\multicolumn{2}{|c|}{$\begin{array}{l}\text { 9. SPONSORING/MONITORING AGENCY NAME(S) AND ADDRESS(ES) } \\
\text { National Aeronautics and Space Administration } \\
\text { Washington, DC 20546-0001 }\end{array}$}} & $\begin{array}{l}\text { 10. SPONSORING/MONITOR'S } \\
\text { ACRONYM(S) } \\
\text { NASA }\end{array}$ \\
\hline & & $\begin{array}{l}\text { 11. SPONSORING/MONITORING } \\
\text { REPORT NUMBER } \\
\text { NASA/TM-2011-217225 }\end{array}$ \\
\hline \multicolumn{3}{|c|}{$\begin{array}{l}\text { 12. DISTRIBUTION/AVAILABILITY STATEMENT } \\
\text { Unclassified-Unlimited } \\
\text { Subject Category: } 07 \text { and } 64 \\
\text { Available electronically at http://www.sti.nasa.gov } \\
\text { This publication is available from the NASA Center for AeroSpace Information, 443-757-5802 }\end{array}$} \\
\hline
\end{tabular}

\section{SUPPLEMENTARY NOTES}

\section{ABSTRACT}

NASA's Environmentally Responsible Aviation Project and Subsonic Fixed Wing Project are focused on developing concepts and technologies which may enable dramatic reductions to the environmental impact of future generation subsonic aircraft (Refs. 1 and 2). The open rotor concept (also referred to as the Unducted Fan or advanced turboprop) may allow the achievement of this objective by reducing engine emissions and fuel consumption. To evaluate its potential impact, an open rotor cycle modeling capability is needed. This paper presents the initial development of an open rotor cycle model in the Numerical Propulsion System Simulation (NPSS) computer program which can then be used to evaluate the potential benefit of this engine. The development of this open rotor model necessitated addressing two modeling needs within NPSS. First, a method for evaluating the performance of counter-rotating propellers was needed. Therefore, a new counter-rotating propeller NPSS component was created. This component uses propeller performance maps developed from historic counter-rotating propeller experiments to determine the thrust delivered and power required. Second, several methods for modeling a counter-rotating power turbine within NPSS were explored. These techniques used several combinations of turbine components within NPSS to provide the necessary power to the propellers. Ultimately, a single turbine component with a conventional turbine map was selected. Using these modeling enhancements, an open rotor cycle model was developed in NPSS using a multi-design point approach. The multi-design point (MDP) approach improves the engine cycle analysis process by making it easier to properly size the engine to meet a variety of thrust targets throughout the flight envelope. A number of design points are considered including an aerodynamic design point, sea-level static, takeoff and top of climb. The development of this MDP model was also enabled by the selection of a simple power management scheme which schedules propeller blade angles with the freestream Mach number. Finally, sample open rotor performance results and areas for further model improvements are presented.

\section{SUBJECT TERMS}

Counter-rotating propellers; Propellers; Turboprop engines; Gas turbine engines

\begin{tabular}{|c|c|c|c|c|c|}
\hline \multicolumn{3}{|c|}{ 16. SECURITY CLASSIFICATION OF: } & \multirow{2}{*}{$\begin{array}{l}\text { 17. LIMITATION OF } \\
\text { ABSTRACT } \\
\text { UU }\end{array}$} & \multirow{2}{*}{$\begin{array}{l}\text { 18. NUMBER } \\
\text { OF } \\
\text { PAGES } \\
17\end{array}$} & \multirow{2}{*}{$\begin{array}{l}\text { 19a. NAME OF RESPONSIBLE PERSON } \\
\text { STI Help Desk (email:help@sti.nasa.gov) } \\
\text { 19b. TELEPHONE NUMBER (include area code) } \\
\text { 443-757-5802 }\end{array}$} \\
\hline $\begin{array}{l}\text { a. REPORT } \\
U\end{array}$ & $\begin{array}{l}\text { b. ABSTRACT } \\
U\end{array}$ & $\begin{array}{l}\text { c. THIS } \\
\text { PAGE } \\
\text { U }\end{array}$ & & & \\
\hline
\end{tabular}



